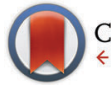

CrossMark \& click for updates

Cite this: J. Mater. Chem. C, 2016, 4, 5031

Received 1st February 2016 Accepted 25th April 2016

DOI: $10.1039 / c 6 t c 00493 h$

www.rsc.org/MaterialsC

\title{
Facile preparation of copper nitride powders and nanostructured films $\dagger$
}

\author{
Robert Szczęsny, ${ }^{\text {ab }}$ Edward Szłyk, ${ }^{b}$ Marek A. Wiśniewski, ${ }^{\text {bc }}$ Tuan K. A. Hoang ${ }^{a}$ and \\ Duncan H. Gregory ${ }^{\star a}$
}

\begin{abstract}
The simple fluorinated precursor, copper(II) trifluoroacetate, $\mathrm{Cu}\left(\mathrm{CF}_{3} \mathrm{COO}\right)_{2}$ can be effectively utilised in the synthesis of copper(I) nitride, $\mathrm{Cu}_{3} \mathrm{~N}$, powders and films by combinations of wet processing and gas-solid (ammonolysis) techniques. The resulting materials were characterized by powder X-ray diffraction (PXD), scanning electron microscopy (SEM) with energy dispersive $X$-ray spectroscopy (EDX), atomic force microscopy (AFM), diffuse reflectance UV-visible spectroscopy (DRUV-Vis), Raman spectroscopy, infrared spectroscopy (IR), thermogravimetric-differential thermal analysis-mass spectrometry (TG-DTA-MS) and nitrogen adsorption (BET) analysis. Moreover, variable temperature IR (VT-IR) studies of the solid phase were performed in situ during ammonolysis. Single-phase $\mathrm{Cu}_{3} \mathrm{~N}$ powders composed of submicron scale platelets can be produced over relatively short reaction times. Materials prepared in this way are stoichiometric narrow band gap semiconductors. The same trifluoroacetate precursor was used to prepare nanostructured nitride films by spin coating. The surface microstructure was investigated and evaluated relative to films deposited by dip coating and nebulisation using the soluble carboxylate precursor
\end{abstract}

\section{Introduction}

Copper nitride is an indirect band-gap semiconductor with a high electrical resistivity and a low reflectivity which can find potential application in optical storage, ${ }^{1-4}$ as a component of spintronic systems $^{5,6}$ or as a potential electrode material for rechargeable Li-ion batteries. ${ }^{7}$ Coatings of $\mathrm{Cu}_{3} \mathrm{~N}$ can also be used to generate microscopic metal lines and dots since copper nitride is thermally unstable and can easily decompose into nitrogen and pure metallic copper. $^{8}$ The deposited copper metal has a significantly higher reflectivity and conductivity than the nitride and this decomposition process can be easily induced by electron beam or laser irradiation. In contrast to tellurium-based light recording media, $\mathrm{Cu}_{3} \mathrm{~N}$ is non-toxic and stable at ambient conditions. ${ }^{9}$ Consequently, the nitride can be used for the fabrication of either metallic $\mathrm{Cu}$ or composite $\mathrm{Cu} / \mathrm{Cu}_{3} \mathrm{~N}$ microscopic structures. ${ }^{10}$ Structures of this type can be employed as the basis of advanced magnetic devices such as spin valves ${ }^{6}$ or used to probe complex nanoscale phenomena such as the spin excitations of Mn antiferromagnetic chains. ${ }^{5}$ $\mathrm{Cu}_{3} \mathrm{~N}$ has a cubic anti- $\mathrm{ReO}_{3}$ type structure (space group $P m \overline{3} m$ )

\footnotetext{
${ }^{a}$ WestCHEM, School of Chemistry, University of Glasgow, Glasgow, G12 8QQ, UK. E-mail: Duncan.Gregory@Glasgow.ac.uk

${ }^{b}$ Nicolaus Copernicus University in Toruń, Faculty of Chemistry, 87-100 Toruń, Poland. E-mail: Robert.Szczesny@umk.pl

c INVEST-TECH R\&D Center, 32-34 Plaska St., 87-100 Toruń, Poland

$\dagger$ Electronic supplementary information (ESI) available. See DOI: 10.1039/ c6tc00493h
}

where nitrogen atoms are located at the corners of the primitive unit cell and copper atoms occupy the $3 d$ edge sites. Given the open nature of the structure, in some circumstances it is possible to insert metal atoms at the interstitial body centre $(1 / 2,1 / 2,1 / 2)$ position. ${ }^{11,12}$ The addition of other transition metals (TMs) modifies the electronic properties of $\mathrm{Cu}_{3} \mathrm{~N}$ and in the case of $3 \mathrm{~d}$ metals offers a promising route to produce magnetic semiconductors. ${ }^{3,13}$ Films of copper nitride have been primarily fabricated by physical methods such as reactive RF magnetron sputtering ${ }^{14-16}$ or pulsed laser deposition (PLD) ${ }^{17,18}$ However, chemical synthesis routes to powders of $\mathrm{Cu}_{3} \mathrm{~N}$ predate these studies by several decades. Juza and Rabenau ${ }^{19}$ first synthesized $\mathrm{Cu}_{3} \mathrm{~N}$ in 1956 by heating a $\mathrm{CuF}_{2}$ precursor under a flow of gaseous ammonia. The same precursor was used by Gregory et al. to prepare single phase material for powder neutron diffraction studies. ${ }^{20}$ Further, in 1990 Zachwieja and Jacobs demonstrated that polycrystalline $\mathrm{Cu}_{3} \mathrm{~N}$ could be prepared without the need for ammonia via the direct thermal decomposition reaction of $\left[\mathrm{Cu}\left(\mathrm{NH}_{3}\right)_{x}\right] \mathrm{NO}_{3}{ }^{21}$ It is also possible to synthesise the nitride in a solvothermal reaction by heating copper azide in organic solvents at moderate temperature, ${ }^{22}$ by using $\mathrm{Cu}\left(\mathrm{NO}_{3}\right)_{2}$ and primary amines as capping agents ${ }^{23,24}$ or by reacting ammonia with copper(II) acetate monohydrate dispersed in long chain alcohols. ${ }^{25,26}$ Moreover, it is even possible to utilise copper(I) oxide as a precursor using either ammonia gas or urea as a nitrogen source. ${ }^{27}$

In this work we describe the preparation of copper nitride by ammonolysis of copper trifluoroacetate, $\mathrm{Cu}\left(\mathrm{CF}_{3} \mathrm{COO}\right)_{2}$ for the 
first time. The advantages of using this fluorinated ligand are two-fold: first, previous studies have indicated that the volatility of $\mathrm{Ag}\left(\mathrm{C}_{2} \mathrm{~F}_{5} \mathrm{COO}\right)$ and $\mathrm{Ag}\left(\mathrm{C}_{3} \mathrm{~F}_{7} \mathrm{COO}\right)$ under nitrogen is such that they can decompose at low temperatures via well-defined pathways to yield high purity products. ${ }^{28}$ Therefore, this type of compound has found application in chemical vapour deposition (CVD) processes. ${ }^{29,30}$ Given the standard enthalpy of formation for $\mathrm{Cu}_{3} \mathrm{~N}\left(\Delta H_{\mathrm{f}}=74.5 \mathrm{~kJ} \mathrm{~mol}^{-1}\right),{ }^{31}$ it is vital to perform ammonolysis under a strict temperature regime. In this context, the thermolysis of copper(II) trifluoroacetate should occur below the decomposition temperature of copper nitride. ${ }^{32}$ Second, use of soluble salts offers the opportunity for facile, inexpensive solution-based methods to deposit precursor films for subsequent solid-vapour reactions. Hence, in this article, we report how copper(II) trifluoroacetate can be exploited to produce both powder and thin film samples of copper nitride. In each case, the precursor can be employed under relatively mild conditions to yield sub-micron sized crystalline products.

\section{Experimental}

Copper(II) trifluoroacetate was prepared as reported previously ${ }^{33}$ by reaction of basic copper(II) carbonate (analytical grade, POCh, Poland) with trifluoroacetic acid (99\%, Aldrich) in a water-ethanol solution. The elemental analysis and IR spectra confirmed the composition of the carboxylate.

Ammonolysis experiments were performed in a horizontal tube furnace. In each reaction, up to $0.4 \mathrm{~g}$ of precursor powder was placed in an alumina boat $(60 \times 50 \times 50 \mathrm{~mm})$ and transferred to the furnace. In all cases the maximum temperatures were reached in $\sim 45$ min and $\mathrm{NH}_{3}$ gas (BOC, 99.98\%) was used as the nitriding agent. The detailed experimental conditions are listed in Table 1 . Any adsorbed ammonia was removed by treating post-ammonolysed samples under vacuum $\left(10^{-3}\right.$ torr $)$ at room temperature for $30 \mathrm{~min}$.

All films were deposited onto $10 \mathrm{~mm} \times 10 \mathrm{~mm} \times 1 \mathrm{~mm}$ silicon substrates by spin coating. A saturated solution of copper(II) carboxylate in THF : methanol (ACS, POCh) ( $5: 1)$ was spun onto the substrate at 2000-5000 rpm for 30-120 s and each plate was subsequently dried at a rotation speed of $5000 \mathrm{rpm}$ for $20 \mathrm{~s}$. The coatings were then dried under vacuum for $1 \mathrm{~h}$. Two alternative deposition methods were also assessed. First, the same solution as above was nebulised using a concentric glass nebulizer and the resulting mist was swept onto the silicon plate using

Table 1 Experimental conditions for samples prepared by ammonolysis

\begin{tabular}{llll}
\hline Sample no. & Temperature $/{ }^{\circ} \mathrm{C}$ & Time $/$ min & Product phases from PXD \\
\hline $\mathbf{1}$ & 250 & 180 & Amorphous \\
$\mathbf{2}$ & 300 & 45 & $\mathrm{Amorphous}$ \\
$\mathbf{3}$ & 300 & 240 & $\mathrm{Cu}_{3} \mathrm{~N}$ \\
$\mathbf{4}$ & 310 & 300 & $\mathrm{Cu}_{3} \mathrm{~N}$ \\
$\mathbf{5}$ & 350 & 180 & $\mathrm{Cu}_{3} \mathrm{~N}(99 \mathrm{wt} \%) \mathrm{Cu}(1 \mathrm{wt} \%)^{a}$ \\
$\mathbf{6}$ & 350 & 240 & $\mathrm{Cu}_{3} \mathrm{~N}(95 \mathrm{wt} \%) \mathrm{Cu}(5 \mathrm{wt} \%)^{a}$
\end{tabular}

${ }^{a}$ Phase fractions (wt $\%$ ) were estimated using profile fitting within the PowderCell software. ${ }^{34}$
Table 2 Designations for deposited samples with respective spin-coating parameters as applicable

\begin{tabular}{llll}
\hline Sample & $\begin{array}{l}\text { Deposition conditions } \\
\text { time/s; speed/rpm }\end{array}$ & Sample & $\begin{array}{l}\text { Deposition conditions } \\
\text { time/s; speed/rpm }\end{array}$ \\
\hline $\mathbf{A}$ & $10 ; 500$ & $\mathbf{J}$ & $30 ; 3000$ \\
$\mathbf{B}$ & $120 ; 2000$ & $\mathbf{K}$ & $60 ; 4000$ \\
$\mathbf{C}$ & $30 ; 2000$ & $\mathbf{L}$ & $120 ; 4000$ \\
$\mathbf{D}$ & $60 ; 3000$ & $\mathbf{M}$ & $180 ; 5000$ \\
$\mathbf{E}$ & $30 ; 4000$ & $\mathbf{N}$ & $180 ; 3000$ \\
$\mathbf{F}$ & $60 ; 5000$ & $\mathbf{O}$ & $10 ; 4000$ \\
$\mathbf{G}$ & $300 ; 5000$ & $\mathbf{P}$ & Nebulisation \\
$\mathbf{H}$ & $10 ; 5000$ & $\mathbf{R}$ & Dip-coating \\
$\mathbf{I}$ & $30 ; 1000$ & &
\end{tabular}

compressed nitrogen. The carboxylate solution was deposited onto the plates in $\sim 30 \mathrm{~s}$ and the nozzle-substrate distance was $15 \mathrm{~cm}$. Second, comparative dip-coating was performed using a solution of $\mathrm{Cu}\left(\mathrm{CF}_{3} \mathrm{COO}\right)_{2}$, which was prepared by dissolution of $0.1 \mathrm{~g}$ of the copper salt in $30 \mathrm{ml}$ of ethylene glycol. The silica plates used as substrates for deposition were immersed and withdrawn vertically in the solution and dried in air. The process was repeated sequentially 10 times for each sample. Ammonolysis of the films was performed at $310{ }^{\circ} \mathrm{C} / 300 \mathrm{~min}$ or $300{ }^{\circ} \mathrm{C} / 240 \mathrm{~min}$. The film formation parameters are listed in Table 2.

Bulk powder products were characterized by PXD using Philips XPERT Pro $\theta-2 \theta$ and Bruker D8 diffractometers with $\mathrm{CuK} \alpha 1$ and $\mathrm{CuK} \alpha$ radiation, respectively. Phase identification was performed by search-match procedures with access to the ICDD powder diffraction file (PDF) and by comparison to patterns generated from ICSD data using PowderCell v.2.3. ${ }^{34}$ Structure refinement was performed using the GSAS-II program package, ${ }^{35}$ (data were collected from $10 \leq 2 \theta /^{\circ} \leq 110$, with a step size of $0.0084^{\circ} 2 \theta$ and at a scanning rate of $0.02^{\circ} \mathrm{min}^{-1}$ ). Scanning electron microscopy (SEM) studies were performed with three instruments: (1) a LEO 1430 VP microscope (Cambridge Ltd) equipped with a Quantax 200 spectrometer (XFlash 4010 detector, Bruker AXS) for energy dispersive X-ray (EDX) spectroscopy ( $\mathrm{HV}$ mode, SE, EHT $=10-20 \mathrm{kV}$, beam current $100 \mu \mathrm{A}$ ); (2) a Philips XL 30 environmental (E)SEM equipped with an Oxford Instruments INCA Energy 250 EDX system $(\mathrm{EHT}=20 \mathrm{kV}$, spot size 5) and (3) a Quanta 3D FEG (EHT $=30 \mathrm{kV})$ instrument. Samples of powders and films deposited onto Si were placed onto carbon tabs attached to aluminium SEM stubs. All samples were analysed in the microscope without coating treatment. Atomic Force Microscopy (AFM) analysis of films was performed using a Veeco microscope (Digital Instruments) with an NSG-11 probe (scan size 2-10 $\mu \mathrm{m}$; scan rate $1 \mathrm{~Hz}$, tapping mode).

The IR spectra (including diffuse reflectance spectra; DRIFTS) of precursors, powder products and films were obtained using a Perkin-Elmer 2000 FT IR spectrometer. Raman spectra of copper nitride were collected at room temperature using a Horiba LabRAM HR confocal microscope system with a $532 \mathrm{~nm}$ green laser. Diffuse reflectance (DR) UV-Vis spectra (using a Varian Cary 500 Spectrophotometer) were used to measure the optical band-gap energy of powder samples. Absorption was measured over wavelengths from 300-2000 $\mathrm{nm}$. 
Additionally, in situ FTIR studies (using a Mattson-Genesis II spectrometer) were performed of the heterogeneous reactions of $\mathrm{Cu}\left(\mathrm{CF}_{3} \mathrm{COO}\right)_{2}$ films loaded on mica and exposed to an $\mathrm{NH}_{3}$ atmosphere. The composition of the gas phase in contact with the sample was also monitored by FTIR. Single beam spectra with only gases in the beam and spectra with both the sample and gases in the beam were taken. The ratio of these spectra allows the gaseous absorption to be subtracted, giving the absorbance due to modification of the $\mathrm{Cu}\left(\mathrm{CF}_{3} \mathrm{COO}\right)_{2}$ film. Additionally, the attenuated total reflectance (ATR) technique (using a SPECAC Silver Gate with Ge crystal) was employed to characterise the final product of the ammonolysis.

The thermal behaviour of copper nitride powders was investigated by thermogravimetric-differential thermal analysis (TG-DTA) under a flowing argon atmosphere using a Netzsch STA 409PC TG-DTA instrument coupled to evolved gas analysis by MS (Hiden HPR20 mass spectrometer). Samples were heated from $30-500{ }^{\circ} \mathrm{C}$ at a heating rate of $5{ }^{\circ} \mathrm{C} \min ^{-1}$ and maintained at this temperature for $2 \mathrm{~h}$. The surface areas of the synthesized materials were determined by applying the BET method to nitrogen adsorption-desorption data, which were collected at liquid nitrogen temperature using a Micromeritics Gemini instrument.

\section{Results and discussion}

\section{$\mathrm{Cu}_{3} \mathrm{~N}$ powder characterisation}

Synthesis, compositional, thermal and morphological analysis. IR spectra were collected for $\mathrm{Cu}\left(\mathrm{CF}_{3} \mathrm{COO}\right)_{2}$ and the resultant nitride powders obtained by heating the salt in ammonia. Spectra of the precursor samples showed the characteristic carboxylate, $\mathrm{COO}\left(1716\left(\nu_{\mathrm{s}}\right), 1453 \mathrm{~cm}^{-1}\left(\nu_{\mathrm{s}}\right)\right)$ and $\mathrm{CF}_{3}$ group (1106, 1176, $1251 \mathrm{~cm}^{-1}$ ) stretching bands. After reaction with ammonia these bands are no longer present in any of the samples 1-6 (see Table 1) and new, strong bands appear. According to the literature the $\mathrm{Cu}-\mathrm{N}$ lattice vibration occurs at $\sim 650 \mathrm{~cm}^{-1}$ as a sharp signal. ${ }^{36}$ Experiments carried out at $250{ }^{\circ} \mathrm{C}$ yielded a sharp band at $653 \mathrm{~cm}^{-1}$ plus additional bands at $669 \mathrm{~cm}^{-1}$ and $520 \mathrm{~cm}^{-1}$ (broad). In fact, the most intense IR absorption peaks in the spectrum occur at $3425(\nu(\mathrm{O}-\mathrm{H})$ or $\nu(\mathrm{N}-\mathrm{H})), 1626(\nu(\mathrm{C}=\mathrm{N})$ or $\nu(\mathrm{C}=\mathrm{C})), 1441 \mathrm{~cm}^{-1}, 1115 / 1048 \mathrm{~cm}^{-1}(\nu(\mathrm{C}=\mathrm{C}), \nu(\mathrm{C}=\mathrm{N})$ or $\mathrm{C}-\mathrm{H}$ deformation vibration bonding types) and $2926(\nu(\mathrm{C}-\mathrm{H}))$ (Fig. S1, ESI $\dagger$ ). ${ }^{37}$ The presence of these bands would strongly indicate that the reaction is not complete. In the case of experiment $2\left(300{ }^{\circ} \mathrm{C}, 45 \mathrm{~min}\right)$ a peak at $651 \mathrm{~cm}^{-1}$ was registered, although this broad band cannot be unambiguously associated with the presence of nitride. Other IR bands for 2 appear at 1146, 1560,2130 and $3328 \mathrm{~cm}^{-1}$ and can be related to the vibration of single and multiple $\mathrm{C}-\mathrm{N}$ bonds and $\mathrm{N}-\mathrm{H}$ bonds (Fig. S2, ESI $\dagger$ ). By following the ammonolysis reaction in situ, the FTIR results reveal several steps over the course of the reaction (Fig. 1). The spectrum of dehydrated $\mathrm{Cu}\left(\mathrm{CF}_{3} \mathrm{COO}\right)_{2}$ (Fig. 1a) consists mainly of bands that can be attributed to carboxylates (1667 and $1470 \mathrm{~cm}^{-1}$ ) and $\mathrm{CF}_{3}$ groups (1198 and $1151 \mathrm{~cm}^{-1}$ ). When the sample is exposed to an ammonia atmosphere, ammonium salts

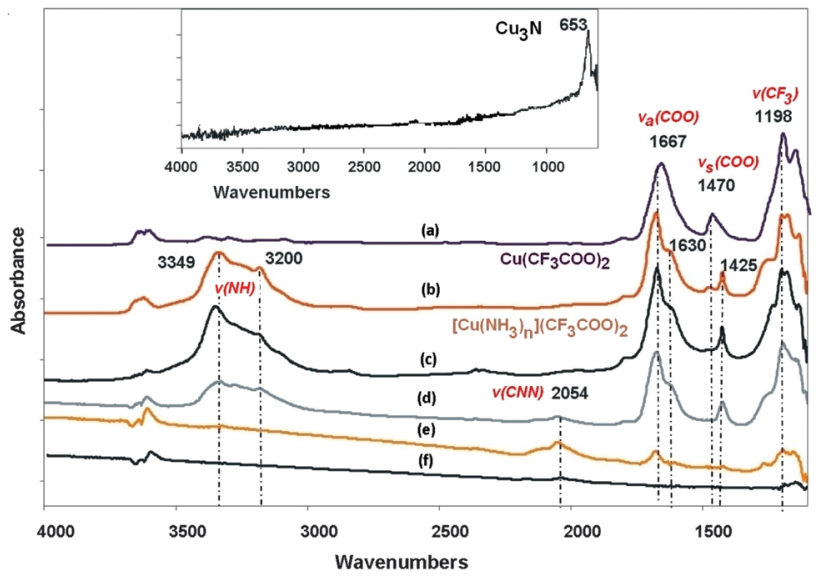

Fig. 1 In situ FTIR spectra collected as a function of temperature before and during ammonolysis showing: (a) the $\mathrm{Cu}\left(\mathrm{CF}_{3} \mathrm{COO}\right)_{2}$ precursor dehydrated at $120^{\circ} \mathrm{C}$ and the sample under ammonia at: (b) $25^{\circ} \mathrm{C}$, (c) $150{ }^{\circ} \mathrm{C}$, (d) $175^{\circ} \mathrm{C}$, (e) $200{ }^{\circ} \mathrm{C}$, (f) $310{ }^{\circ} \mathrm{C}$ respectively. Inset - the ATR spectrum of the sample after heating under ammonia gas at $310^{\circ} \mathrm{C}$.

begin to form readily at room temperature (Fig. 1b) and the characteristic bands of the precursor decrease while new signals of $\left[\mathrm{Cu}\left(\mathrm{NH}_{3}\right)_{n}\right]\left(\mathrm{CF}_{3} \mathrm{COO}\right)_{2}$ appear at 1630 and $1425 \mathrm{~cm}^{-1}$. A rise in temperature to $150{ }^{\circ} \mathrm{C}$ (Fig. 1c) results in no changes to the spectrum, but by $175{ }^{\circ} \mathrm{C}$ the intensities of all the established IR signals decrease and a new band appears at $2050 \mathrm{~cm}^{-1}$.

According to the literature, the new band could be assigned to a CNN stretch. ${ }^{37}$ By $310{ }^{\circ} \mathrm{C}$, the band at $2050 \mathrm{~cm}^{-1}$ is no longer present and the only feature in the spectrum is the band attributable to $\mathrm{Cu}_{3} \mathrm{~N}\left(650 \mathrm{~cm}^{-1}\right.$, Fig. 1 inset). Near-identical IR spectra were obtained for samples 3-6.

Significantly, the powder X-ray diffraction patterns of $\mathbf{1}$ and $\mathbf{2}$ contained no Bragg peaks and hence did not reveal any crystalline phases. In contrast, powder patterns obtained for samples 3-6 clearly demonstrate the presence of $\mathrm{Cu}_{3} \mathrm{~N}$ (Fig. 2 and Fig. S3, ESI $\dagger$ ). In the case of thin films deposited on mica, copper nitride reflections dominate with some traces of metallic copper also observed (Fig. S4 and S5, ESI $\dagger$ ). The Raman spectra of 3-6 reveal peaks at 275 and $610 \mathrm{~cm}^{-1}$. According to the literature, the two bands at 220 and $634 \mathrm{~cm}^{-1}$ are indicative of copper nitride ${ }^{38}$ corroborating the results above from FTIR spectroscopy.

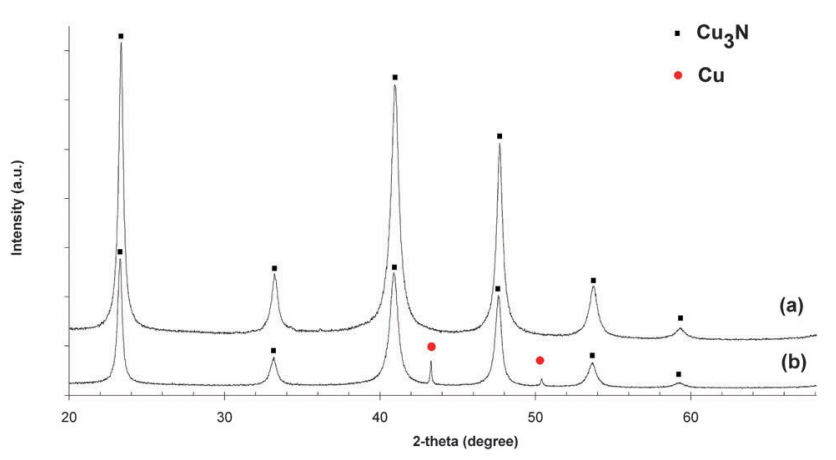

Fig. 2 X-ray diffraction patterns of (a) 3 (prepared at $300{ }^{\circ} \mathrm{C}, 240 \mathrm{~min}$ ) and (b) 6 (350 $\left.{ }^{\circ} \mathrm{C}, 240 \mathrm{~min}\right)$. 
Thermogravimetric-differential thermal analysis (TG-DTA) performed for 3 under flowing argon demonstrates that the sample is thermally stable up to $349{ }^{\circ} \mathrm{C}$. Above this temperature the product starts to decompose to $\mathrm{Cu}$ and $\mathrm{N}_{2}$ (as indicated by the MS spectrum of the evolved gas). This process corresponds to a mass loss of $7.0 \%$ ( $c f$. the theoretical nitrogen content of $6.8 \mathrm{wt} \%$ ).

SEM/EDX analyses were used to investigate the morphology and elemental composition of materials produced under different conditions. Samples 1 and 2 took the form of a dense mass or cake of agglomerated powders (Fig. 3a). EDX spectra yielded elemental compositions with $\mathrm{Cu}: \mathrm{N}: \mathrm{F}$ ratios of $1: 0.4: 0.6$ (RSD [\%] Cu: $\mathrm{N}: \mathrm{F}=3: 19: 15)$ and $1: 1.8: 0.1(\mathrm{RSD}[\%] \mathrm{Cu}: \mathrm{N}: \mathrm{F}=$ $3: 16: 33$ ) for 1 and 2 respectively. The elemental ratios can be rationalized in terms of the progress of the ammonolysis reaction. In the initial stages of the reaction, $\mathrm{NH}_{3}$ partially reacts with the precursor to induce formation of carbon-nitrogen bonds. Although 1 and 2 are X-ray amorphous, these bonds are visible as bands in the IR spectra. Given the relatively high nitrogen content of sample 2 , we can assume that the temperature has a major impact on the conversion process (regardless of the reduced reaction time compared to 1 ). Volatile species are likely formed during ammonolysis at higher reaction temperatures, finally resulting in the reduction to elemental copper (samples 5 and 6) (as indicated by PXD in Fig. 2). Complete conversion to $\mathrm{Cu}_{3} \mathrm{~N}$ without further reduction was observed for samples 3 and $\mathbf{4}$ and EDX analysis of 3 yielded a $\mathrm{Cu}: \mathrm{N}$ ratio of ca. 2.8:1 (RSD [\%] $\mathrm{Cu}: \mathrm{N}=3: 7$ ). Moreover, SEM micrographs demonstrated that $\mathbf{3}$ and $\mathbf{4}$ form as a porous matrix of submicron sized particles. Each faceted particle is of the order of 200-500 nm in diameter (Fig. 3b).

Optical and surface area characterisation. DRUV-Vis spectroscopy was conducted at room temperature to determine the optical band gap $\left(E_{\mathrm{g}}\right)$ of copper nitride powder. The value of $E_{\mathrm{g}}$ was obtained by implementing the Kubelka-Munk (K-M) function and extracting the value from Tauc plots (Fig. S3, ESI $\dagger$ ) ${ }^{39-41} \mathrm{~A}$ calculated band gap energy of $1.48 \mathrm{eV}$ was obtained, which is similar to many of the values reported in the literature. Various theoretical calculations show that copper nitride is an indirect semiconducting material with a band gap between $0.23 \mathrm{eV}$ and $0.9 \mathrm{eV}^{42-45}$ However, there continues to be active discussion regarding the width of the band gap and whether it is indirect or direct. Values determined experimentally vary, for example, between $0.25-1.9 \mathrm{eV}$ for films deposited by sputtering methods, ${ }^{45,46}$
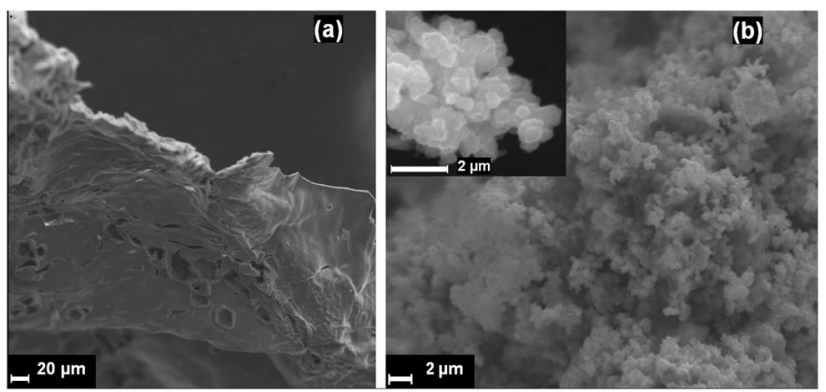

Fig. 3 SEM images illustrating the contrast in microstructure for (a) 1 and (b) $\mathbf{3}$; inset - higher magnification image of $\mathbf{3}$. whereas a gap of $1 \mathrm{eV}$ was reported for microcrystalline powders treated at high pressure and high temperature ${ }^{47}$ and gaps of $1.04 \mathrm{eV}$ (indirect) and $1.5 \mathrm{eV}$ (direct) were calculated from cyclic voltammetry $(\mathrm{CV})$ data for $\mathrm{Cu}_{3} \mathrm{~N}$ nanocubes. ${ }^{48}$ In the case of $\mathrm{Cu}_{3} \mathrm{~N}$ films, there appears to be a measureable dependence between the band gap and the copper and nitrogen content in the film (with an apparent dependence in turn on the synthesis conditions). In general, the differences in the optical band gap values can originate from the preparation methods, crystal size and shape $\left(E_{\mathrm{g}}\right.$ decreases with an increase in the crystallite size $^{49,50}$ ) and from the degree of structural order-disorder in the lattice. $^{51,52}$

Nitrogen adsorption-desorption isotherms of sample 3 could be classified as type II, which represent nonporous solids (Fig. S3, $\mathrm{ESI} \dagger) .{ }^{53}$ The adsorption isotherm is essentially linear in the range of $P / P_{0}=0-0.7$ and condensation adsorption emerges in the region from $P / P_{0} \sim 0.8$ to 1.0 . The specific surface area of the sample is relatively low at $3.34 \mathrm{~m}^{2} \mathrm{~g}^{-1}$. The total pore volume is $\sim 0.038692 \mathrm{~cm}^{3} \mathrm{~g}^{-1}$ and reinforces the premise that most of the surface area of the sample is external and that the majority of structural nitrogen species are located in the bulk (as lattice $\mathrm{N}$ atoms) rather than on the (internal or external) surface of the material. ${ }^{54}$

Crystal structure from powder X-ray diffraction data. Rietveld refinement ${ }^{55}$ of the structure of the copper nitride powder obtained at $300{ }^{\circ} \mathrm{C}$ (sample 3) was performed using the anti$\mathrm{ReO}_{3}$ structure of $\mathrm{Cu}_{3} \mathrm{~N}$ reported in ref. 56 as a starting model (in cubic space group $P m \overline{3} m$ ). The refinement conditions and final atomic parameters are listed in Table 3 and an observed, calculated and difference profile plot for the refinement is presented in Fig. 4. The background, zeropoint and scale factor

Table 3 Rietveld refinement and crystallographic parameters for 3

\begin{tabular}{ll}
\hline Radiation & X-ray \\
Instrument & D8 Bruker Advance diffractometer \\
Temperature/K & 293 \\
Formula, $Z$ & $\mathrm{Cu}_{3} \mathrm{~N}, 1$ \\
Crystal system, space group & $\mathrm{Cubic}, P m \overline{3} m$ \\
Lattice parameter, $a / \AA$ & $3.7543(3)$ \\
Cell volume, $V / \AA^{3}$ & $52.917(4)$ \\
No of observations, parameters & 10529,28 \\
$R_{\mathrm{wp}} / \%$ & 3.12 \\
$\chi^{2}$ & 1.29
\end{tabular}

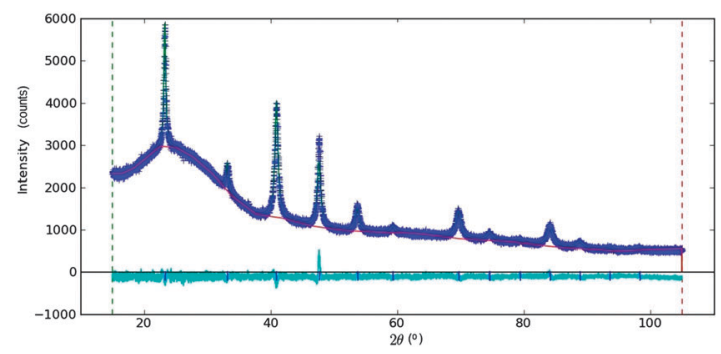

Fig. 4 Rietveld profile plot for 3. Observed data are denoted by dark blue crosses, calculated data by the solid dark green line and the difference profile by the cyan solid line (bottom). Tick marks indicate the reflection positions for $\mathrm{Cu}_{3} \mathrm{~N}$. 
were varied in the initial cycles of the refinement. A log interpolation function with 20 coefficients was applied for background refinement. Cell parameters, profile parameters and atomic parameters were then refined in order. In the final stages, all parameters were refined simultaneously until the residuals were minimized and the refinement reached convergence. Atomic parameters and interatomic distances can be found in the ESI $\dagger$ (Table S1).

\section{Thin film characterisation}

Spin-coating, dip coating and nebulisation experiments with copper trifluoroacetate were used to compare the differences in morphology, size, and size distribution of the microcrystals for each of the different deposition methods. A precursor THF : MeOH solution was used for both spin-coating and nebulisation experiments. The plates were examined by both optical microscopy and SEM following deposition. In most cases it was observed that materials were deposited as separated grains or/and islands of microcrystals and hence the coating layers were discontinuous (Fig. 5a, b and d). The largest islands are tens of microns in size (Fig. $5 \mathrm{~b}$ and c). After the ammoniation process almost spherical particles of the order of $10 \mu \mathrm{m}$ in diameter are clearly visible and each particle is composed of clusters of irregular nanocrystals and wires of sub-micron dimensions (Fig. 5d). However, for some samples uniform and continuous nanometric layers were observed to form between the "islands" (Fig. 5c). In these cases, the island-like structures (Fig. 6a) could be a result of unequal subsequent material deposition into the pinholes of the films. The homogeneous layer consists of grains of several tens of nanometres in size, existing partly in the form of denser agglomerations (Fig. 6b).

As might be expected, variations in the spin coating parameters have a substantial impact on the deposited surface. Irregular randomly distributed aggregates, of a few millimetres
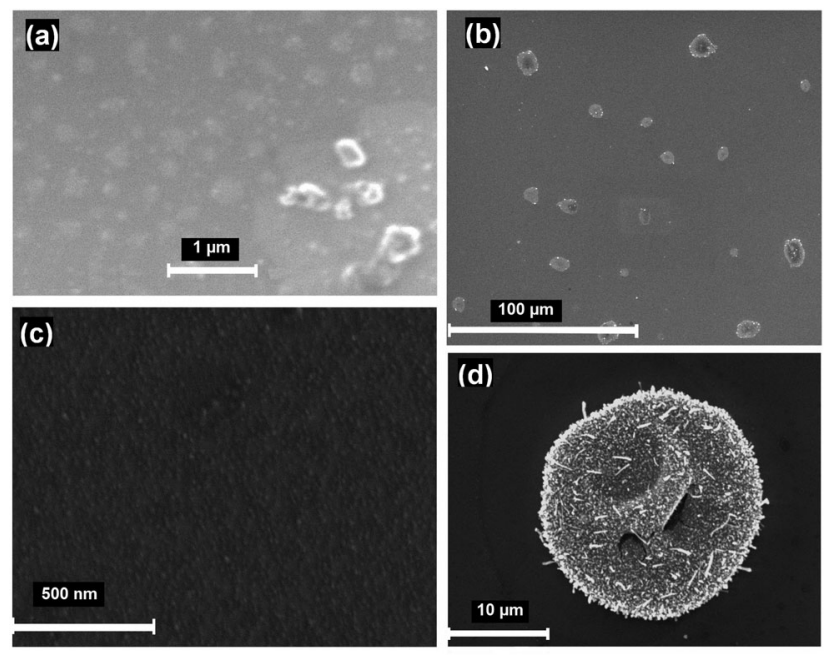

Fig. 5 SEM images of films: (a) as initially deposited on the Si substrate by spin coating (sample D); (b) after deposition by spin coating and subsequent heating under ammonia (sample L); (c) showing a continuous layer in sample L after ammonolysis; (d) showing a single "island" formed after ammonolysis at higher magnification (sample E).
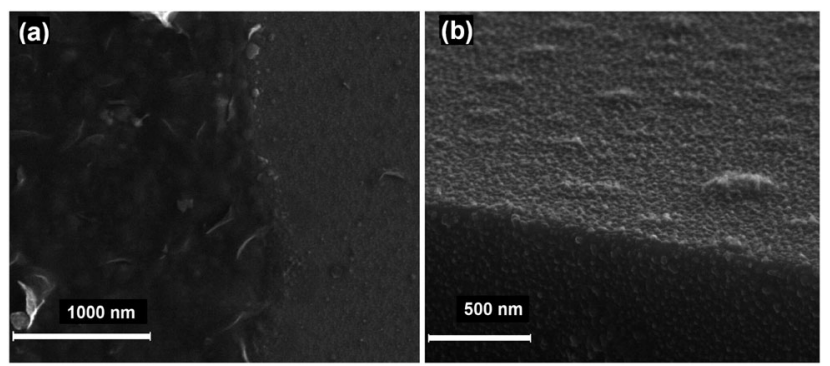

Fig. 6 SEM images of a deposited layer (sample L) showing: (a) the border of the island-like structure (to the left of the image) and a uniform layer (to the right of the image); (b) a cross-section of a homogeneous layer.

in size, are visible at speeds of 500 and $1000 \mathrm{rpm}$. At higher speeds the distribution of the material is much more regular. EDX results confirm that samples $\mathbf{E}, \mathbf{G}$ and $\mathbf{L}$ deposited and heated under ammonia at 300 and $310{ }^{\circ} \mathrm{C}$ contain copper. Nitrogen was present substantially in areas of the film where the coverage was continuous and deposition thickness greatest. These results might suggest that a proportion of deposited copper nitride had decomposed under these conditions and improvements to the compositional homogeneity might be achieved by ammonolysis of the films at lower temperatures (compared to bulk powders). However, we note also that in the case of very thin well-dispersed coatings, the EDX detection limit does not permit unequivocal quantitative identification of light elements such as nitrogen. Indeed, the characteristic sharp band at $c a .660 \mathrm{~cm}^{-1}$ in DRIFT spectra measured from these films strongly corroborates the presence of copper nitride (ESI, $\dagger$ Fig. S6).

The surface morphology and the distribution of the grains after ammonolysis were also investigated by AFM. Fig. 7a shows the AFM image of a spin-coated film of $\mathbf{B}$ deposited from the trifluoroacetate solution and annealed under flowing $\mathrm{NH}_{3}$ at $300{ }^{\circ} \mathrm{C}$ for $4 \mathrm{~h}$. There are two types of distinct particles; small particles are under $50 \mathrm{~nm}$ across with a height of $c a .10 \mathrm{~nm}$ while larger particles form with diverse diameters varying from 150-300 $\mathrm{nm}$ and heights between 70-100 nm. Both types of particle are evenly distributed across the surface of the plate.

The topography of the surface fabricated via nebulisation (sample P, Fig. 7b) is different from the spin-coated samples. By comparison to the spin coated sample, the coverage of the substrate was more complete but islands rather than a continuous

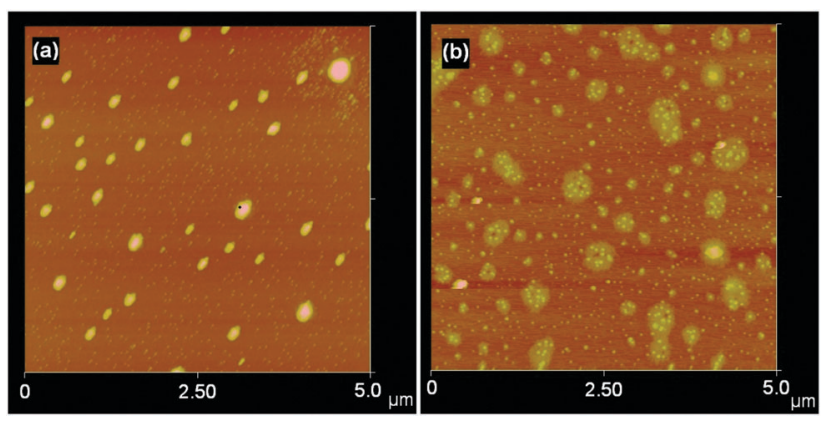

Fig. 7 AFM images of material deposited on to Si substrates and ammonolysed: (a) from spin coating (sample B); (b) via nebulisation (sample P). 


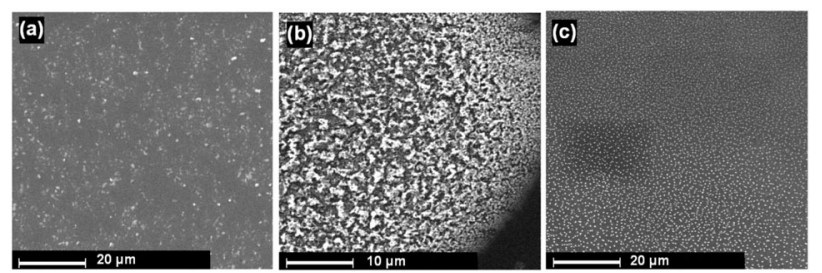

Fig. 8 Representative SEM images of the dip-coated sample (R) after heating under ammonia, showing: (a) the predominant form of the deposited layer and (b), (c) specific areas of the film.

film remained. Individual grains exhibited comparable sizes (50-100 nm across) to those observed in spin coated samples. Additionally, we examined the preparation of $\mathrm{Cu}_{3} \mathrm{~N}$ films by dipping silicon plate substrates in ethylene glycol solutions followed by ammonolysis reactions at $300{ }^{\circ} \mathrm{C}$ (Fig. 8). As for spin coated and nebulized samples, the films have non-uniform distributions and only partially cover the silicon plates. This results in areas across the substrate with different concentrations of the deposited material. The most common observed topography is shown in Fig. 8a. In this case, EDX analysis produced no convincing evidence for nitrogen in these films. Similar elemental analysis results were recorded for areas containing more densely packed material (Fig. 8b). By contrast, the presence of nitrogen was confirmed in the areas of films that were the most uniform in coverage (consisting of fine grains of average size about 300 nm; Fig. 8c).

Deposition and ammonolysis experiments suggest therefore that future studies should focus on optimizing processing methods to improve the quality and homogeneity of the films. Moreover, results suggest that the ammonolysis of nanostructured films deposited onto silicon may require milder conditions (e.g. lower temperature) than the equivalent process for bulk powders.

To the best of our knowledge, there are no previously published studies concerning fabrication of $\mathrm{Cu}_{3} \mathrm{~N}$ films by chemical deposition methods. In fact, so-called "wet chemistry methods" have been utilised relatively rarely for preparation of any nitride films. Among previous examples are the formation of silicon nitride films using a sol-gel process combined with dip-coating ${ }^{57}$ and the preparation of smooth, crack-free boron nitride films by spin coating. ${ }^{58}$ In this latter case, the nitride film was obtained by spinning a polyborazine precursor onto a substrate, followed by pyrolysis.

Application of solution methods to prepare metal nitride thin films are sparse. ${ }^{59}$ Noteworthy, is a report by Luo et al. describing the polymer-assisted deposition (PAD) of a series of metal-nitride layers such as TiN, AlN, GaN and NbN. ${ }^{60,61}$ In the PAD process, the polymer not only controls the viscosity of the metal-polymer solution but can also bind the metal ions often facilitating a homogenous distribution of the precursor. From our own experimental data and from those in the literature, it can be presumed that the selection of solvent (solutions) plays an important role in the deposition and can have a positive impact on enhanced film uniformity. Pinholes such as those observed in our experiments usually indicate a local de-wetting and defects such as pinholes and "islands" were also observed for films produced by the PAD process. ${ }^{62}$ Hence, although both results herein and by PAD suggest that near-uniform layers can be deposited, optimisation of these processes seems to be the most important task towards achieving defect-free films. The previous studies and the work described herein should act as an incentive to researchers to continue to expend effort in developing relatively inexpensive and easy chemical methods for deposition of nanostructured nitride films.

\section{Conclusions}

Sub-micron powders of $\mathrm{Cu}_{3} \mathrm{~N}$ can be produced by ammonolysis reactions using $\mathrm{Cu}\left(\mathrm{CF}_{3} \mathrm{COO}\right)_{2}$ as precursor over a temperature range of $300-310{ }^{\circ} \mathrm{C}$. Annealing in an ammonia atmosphere at $350{ }^{\circ} \mathrm{C}$ or higher leads to $\mathrm{Cu}_{3} \mathrm{~N}$ decomposition accompanied by reduction of copper(II) to metallic copper. The value of the band gap for powders produced from copper(II) trifluoroacetate was $1.48 \mathrm{eV}$ and is comparable with literature data for the nitride. BET measurements classify the powders as nonporous solids. The use of carboxylate solution-based precursors provides a facile route to nitride thin film deposition and the quality and structure of these films can be controlled via appropriate choice of precursor and processing conditions.

\section{Acknowledgements}

The study was supported by a research fellowship for R. S. within the "Enhancing the Educational Potential of Nicolaus Copernicus University in the Disciplines of Mathematical and Natural Sciences" project (project no. POKL.04.01.01-00-081/10). D. H. G thanks EPSRC for funding for T. K. A. H. under grant EP/I022570/1.

\section{Notes and references}

1 Z. Ji, Y. Zhang, Y. Yuan and C. Wang, Mater. Lett., 2006, 60, 3758.

2 R. Cremer, M. Witthaut, D. Neuschütz, C. Trappe, M. Laurenzis, O. Winkler and H. Kurz, Microchim. Acta, 2000, 133, 299.

3 X. Y. Cui, A. Soon, A. E. Phillips, R. K. Zheng, Z. W. Liu, B. Delley, S. P. Ringer and C. Stampil, J. Magn. Magn. Mater., 2012, 324, 3138.

4 G. H. Yue, P. X. Yan, J. Z. Liu, M. X. Wang, M. Li and X. M. Yuan, J. Appl. Phys., 2005, 98, 103506.

5 C. F. Hirjibehedin, C. P. Lutz and A. J. Heinrich, Science, 2006, 312, 1021.

6 C. Navio, J. Alvarez, M. J. Capitan, J. Camarero and R. Miranda, Appl. Phys. Lett., 2009, 94, 263112.

7 N. Pereira, L. Dupont, J. M. Tarascon, L. C. Klein and G. G. Amatucci, J. Electrochem. Soc., 2003, 150, A1273.

8 T. Nosaka, M. Yoshitakea, A. Okamoto, S. Ogawa and Y. Nakayama, Appl. Surf. Sci., 2001, 169-170, 358.

9 T. Maruyama and T. Morishita, Appl. Phys. Lett., 1996, 69, 890.

10 D. M. Borsa, S. Grachev, C. Presura and D. O. Boerma, Appl. Phys. Lett., 2002, 80, 1823. 
11 J. F. Pierson and D. Horwat, Scr. Mater., 2008, 58, 568.

12 U. Hahn and W. Weber, Phys. Rev. B: Condens. Matter Mater. Phys., 1996, 53, 12684.

13 J. N. Ding, N. Y. Yuan, F. Li, G. Q. Ding, Z. G. Chen, X. S. Chen and W. Lu, J. Chem. Phys., 2009, 131, 174102.

14 Z. Q. Liu, W. J. Wang, T. M. Wang, S. Chao and S. K. Zheng, Thin Solid Films, 1998, 325, 55.

15 J. Wang, J. T. Chen, X. M. Yuan, Z. G. Wu, B. B. Miao and P. X. Yan, J. Cryst. Growth, 2006, 286, 407.

16 X. Y. Fan, Z. G. Wu, P. X. Yan, B. S. Geng, H. J. Li, C. Li and P. J. Zhang, Mater. Lett., 2008, 62, 1805.

17 G. Soto, J. A. Díaz and W. de la Cruz, Mater. Lett., 2003, 57, 4130.

18 C. Gallardo-Vega and W. de la Cruz, Appl. Surf. Sci., 2006, 252, 8001.

19 R. Juza and A. Rabenau, Z. Anorg. Allg. Chem., 1956, 285, 212.

20 G. Paniconi, Z. Stoeva, H. Doberstein, R. I. Smith, B. L. Gallagher and D. H. Gregory, Solid State Sci., 2007, 9, 907.

21 U. Zachwieja and H. Jacobs, J. Less-Common Met., 1990, 161, 175.

22 J. Choi and E. G. Gillan, Inorg. Chem., 2005, 44, 7385.

23 H. Wu and W. Chen, J. Am. Chem. Soc., 2011, 133, 15236.

24 P. Xi, Z. Xu, D. Gao, F. Chen, D. Xue, C.-L. Tao and Z.-N. Chen, RSC Adv., 2014, 4, 14206.

25 T. Nakamura, H. Hayashi and T. Ebina, J. Nanopart. Res., 2014, 16, 2699.

26 T. Nakamura, H. Hayashi, T. Hanaoka and T. Ebina, Inorg. Chem., 2014, 53, 710.

27 M. D. Reichert, A. M. White, M. J. Thompson, G. J. Miller and J. Vela, Inorg. Chem., 2015, 54, 6356.

28 E. Szłyk, P. Piszczek, M. Chaberski and A. Goliński, Polyhedron, 2001, 20, 2853.

29 I. Szymańska, P. Piszczek, R. Szczęsny and E. Szłyk, Polyhedron, 2007, 26, 2440.

30 A. Grodzicki, I. Łakomska, P. Piszczek, I. Szymańska and E. Szłyk, Coord. Chem. Rev., 2005, 249, 2232.

31 S. H. Elder, F. J. DiSalvo, L. Topor and A. Navrotsky, Chem. Mater., 1993, 5, 1545.

32 M. Mosiadz, K. L. Juda, S. C. Hopkins, J. Soloducho and B. A. Glowacki, J. Fluorine Chem., 2012, 135, 59.

33 E. Szłyk and I. Szymańska, Polyhedron, 1999, 18, 2941.

34 W. Kraus and G. Nolze, J. Appl. Crystallogr., 1996, 29, 301.

35 GSAS-II-Crystallography Data Analysis Software, https://sub version.xor.aps.anl.gov/trac/pyGSAS.

36 K. Singh, Trans. Faraday Soc., 1971, 67, 2436.

37 M. S. Sam, H. O. Lintang, M. M. Sanagi, S. L. Lee and L. Yuliati, Spectrochim. Acta, Part A, 2014, 124, 357.

38 A. Fallberg, M. Ottosson and J.-O. Carlsson, J. Cryst. Growth, 2010, 312, 1779.

39 J. Tauc, R. Grigorovici and A. Vancu, Phys. Status Solidi, 1966, 15, 627.
40 J. Z. Bloh, R. Dillert and D. W. Bahnemann, Phys. Chem. Chem. Phys., 2014, 16, 5833.

41 J. Navas, A. Sánchez-Coronilla, T. Aguilar, N. C. Hernández, D. M. de los Santos, J. Sánchez-Márquez, D. Zorrilla, C. Fernández-Lorenzo, R. Alcántara and J. Martín-Calleja, Phys. Chem. Chem. Phys., 2014, 16, 3835.

42 M. G. Moreno-Armenta, W. L. Pérez and N. Takeuchi, Solid State Sci., 2007, 9, 166.

43 U. Hahn, W. Weber and W. Weber, Phys. Rev. B: Condens. Matter Mater. Phys., 1996, 53, 12684.

44 J. Wang, J. T. Chen, X. M. Yuan, Z. G. Wu, B. B. Miao and P. X. Yan, J. Cryst. Growth, 2006, 286, 407.

45 D. M. Borsa and D. O. Boerma, Surf. Sci., 2004, 548, 95.

46 J. F. Pierson, Vacuum, 2002, 66, 59.

47 A. Wosylus, U. Schwarz, L. Akselrud, M. G. Tucker, M. Hanfland, K. Rabia, C. Kuntscher, J. von Appen, R. Dronskowski, D. Rau and R. Niewa, Z. Anorg. Allg. Chem., 2009, 635, 1959.

48 H. Wu and W. Chen, J. Am. Chem. Soc., 2011, 133, 15236.

49 R. J. Tayade, P. K. Surolia, R. G. Kulkarni and R. V. Jasra, Sci. Technol. Adv. Mater., 2007, 8, 455.

50 M. Li and J. C. Li, Mater. Lett., 2006, 60, 2526.

51 L. S. Cavalcante, J. C. Sczancoski, R. L. Tranquilin, M. R. Joya, P. S. Pizani, J. A. Varela and E. Longo, J. Phys. Chem. Solids, 2008, 69, 2674.

52 L. S. Cavalcante, A. Z. Simoes, J. C. Sczancoski, V. M. Longo, R. Erlo, M. T. Escote, E. Longo and J. A. Varela, Solid State Sci., 2007, 9, 1020.

53 S. J. Gregg and K. S. W. Sing, Adsorption, Surface Area and Porosity, Academic Press, London, 1982, 2nd edn, pp. 41-110.

54 A.-M. Alexander, J. S. J. Hargreaves and C. Mitchell, Top. Catal., 2012, 55, 1046.

55 H. M. Rietveld, J. Appl. Crystallogr., 1969, 2, 65.

56 R. Juza and H. Hahn, Z. Anorg. Allg. Chem., 1938, 239, 282.

57 S. Hassan, A. L. Hector and A. Kalaji, J. Mater. Chem., 2011, 21, 6370 .

58 J.-G. Kho, K.-T. Moon, G. Nouet, P. Ruterana and D.-P. Kim, Thin Solid Films, 2001, 389, 78.

59 C. Y. Fong, S. S. Ng, F. K. Yam, H. Abu Hassan and Z. Hassan, J. Sol-Gel Sci. Technol., 2013, 68, 95.

60 H. M. Luo, H. Wang, G. F. Zou, E. Bauer, T. M. McCleskey, A. K. Burrell and Q. X. Jia, Trans. Electr. Electron. Mater., 2010, 11, 54 .

61 H. Luo, Y. Lin, H. Wang, J. H. Lee, N. A. Suvorova, A. H. Mueller, A. K. Burrell, T. M. McCleskey, E. Bauer, I. O. Usov, M. E. Hawley, T. G. Holesinger and Q. Jia, Adv. Mater., 2009, 21, 193.

62 T. P. Niesen, M. Puchinger, P. Gerstel, D. Rodewald, J. Wolffa, T. Wagner, J. Bill and F. Aldinger, Mater. Chem. Phys., 2002, 73, 301. 